\title{
Urinary schistosomiasis among basic school children in a new irrigated sugar scheme area, White Nile State, Sudan
}

\begin{abstract}
Urinary Schistosomiasis is a parasitic disease caused by blood flukes of the genus schistosoma and being a major source of morbidity and mortality in tropical and developing countries. The study aim to determine the prevalence rates of Urinary Schistosomiasis among schoolchildren in White Nile State-El Qeteena Locality at White Nile Sugar Scheme a new irrigated Scheme. A school-based descriptive study design was used among basic school children during the period December 2014 to April 2015. The study was conducted in 6 basic schools in the area of White Nile Sugar Scheme at White Nile State-El Qeteena Locality. 480 school children were included in the study. The collected data through the questionnaire and the checklist were analyzed using the SPSS. $11.3 \%$ of the sampled schoolchildren had urinary Schistosomiasis, the highest prevalence of $S$. haematobium was reported in the age group (9-12) years $(55.6 \%)$ followed by the group (5-8) years $(33.3 \%)$. The overall prevalence of $(7.4 \%)$ for female and $(92.6 \%)$ for the male. According to the statistical analysis there was relation between environmental sanitation and the prevalence of infection. Lack of healthy drinking water and inadequate number of latrines were the main factors associated with the disease transmission.
\end{abstract}

Volume 6 Issue 2 - 2018

\author{
Abdelhakam G Tamomh, ${ }^{1,2}$ Adam D Abakar, ${ }^{3}$ \\ BakriYM Nour ${ }^{3,4}$ \\ 'Department of Medical Parasitology and Entomology, \\ University of El Imam El Mahdi, Sudan \\ ${ }^{2}$ College of Medical Laboratory Sciences, Dalian Medical \\ University, China \\ ${ }^{3}$ Department of Parasitology, Gezira University, Sudan \\ ${ }^{4}$ Blue Nile National Institute for Communicable Diseases, \\ Gezira University, Sudan
}

Correspondence: BakriYM Nour, professor of Medical Parasitology, Department of Parasitology, Faculty of Medical Laboratory Sciences, Gezira University, Sudan, Tel +249923579150, Email bakrinour@gmail.com

Received: January 29, 2018 | Published: March 23, 2018

Keywords: urinary schistosomiasis, white nile sugar scheme, prevalence, sudan

\section{Introduction}

Schistosomiasis is a chronic parasitic disease caused by blood flukes of the genus Schistosoma. ${ }^{1}$ Second to malaria, it is the most important parasitic disease in terms of prevalence and mortality rates. ${ }^{2}$ It is considered as the most important water-based disease from a global health perspective. ${ }^{3}$ Schistosomiasis is considered as a neglected tropical disease (NTD); i.e., one of several groups of treatable illnesses that still spread in conditions of poverty, but receive far less attention than required by the suffering they cause. ${ }^{4}$ Some authors attributed such neglect to the long-standing underestimation of its harmful scale owing to the asymptomatic nature of most cases. ${ }^{5}$ The elimination of Schistosomiasis, besides other NTDs, is now recognized as a priority for achieving the Millennium Developmental Goals (MDGs) and targets declared by the United Nations for sustainable poverty reduction in the affected areas of the tropics and subtropics. ${ }^{6}$ The majority of Schistosomiasis cases are prevalent among poor people in sub-Saharan Africa who lack access to health services, safe water, sanitation, and education. Furthermore, the disease helps keep them poor by lessening their ability to work, learn, and contribute to their communities. ${ }^{7}$ In spite of the implementation of control programs, the global distribution of infection has changed over the last half of the twentieth century, but the number of infected people has not reduced. ${ }^{8}$ Schistosomiasis continues to infect millions in poor communities in developing countries and these infections increased around irrigation schemes and dam reservoirs despite the effectiveness and cheapness of Praziquantel. " "An estimated 779 million are at risk of schistosomiasis, of whom 106 million (13.6\%) live in irrigation schemes or in close proximity to large dam reservoirs". ${ }^{9}$ So, School- age children were the primary target of the study because are at highest risk of infection to recent exposure to infection and also early diagnosis and treatment during childhood therefore prevents morbidity. Control of schistosomiasis is of international concern, and the aim of is to reduce morbidity within the definitive host. ${ }^{10}$ Our study aim to determine the prevalence of urinary Schistosomiasis among schoolchildren at the area of White Nile Sugar project as a new irrigated Scheme in Sudan.

\section{Materials and methods}

\section{Study area}

The study was conducted in the White Nile Sugar Scheme which located at Al Kawwa administrative unit in of EL Qeteena localityWhite Nile state, Sudan. Its boundaries are White Nile in the West, Al Gezira state in the East, Al Kawwa town in the south and Wad Elzzaki and El Qeteena town in the North. For more detailed description of the study area see Tamomh et al. ${ }^{11}$

\section{Study design}

A cross sectional descriptive study was conducted to determine the prevalence of Urinary Schistosomiasis in selected basic schools in the study area.

\section{Study population, inclusion and exclusion criteria}

The study was carried out in six basic school children at White Nile Sugar Scheme campus. The pupils were selected randomly, 95 from Abu-Halageem school, 80 from Al-Hidaib school, 90 from Mabroka school, 81 from El-Shaheed Adam Hassan school, 86 from Al-Hefaira school and 48 from Al-Ahamda school. Schoolchildren who are attending school, registered and Newly transferred schoolchildren at 
the time of the visit. Non student, Schoolchildren who were transferred from the school at the time of the visit was excluded as described in Tamomh et al. ${ }^{11}$

\section{Ethical statement}

Ministry of Health in White Nile State, Rabak provided an approval for this study. The study received further approval from the District Education Officer, Prior to the study, the research team conducted meetings with the village executive officers, teachers, and students of selected villages and schools, respectively. During these meetings, the objectives of the study, the study procedures, sampling, and potential risks and discomforts were explained

\section{Samples collection, data collection and processing}

Four hundred and eighty urine samples were collected randomly from selected students. Information was collected regarding individual number, age and sex. Also information includes toilet, father occupation, contact to water (by playing or swimming or bathing), sources of drinking water, and haematuria. Questionnaire was constructed and explained to the students in simple Arabic. Every student was given a dry clean capped plastic bottle to bring his/her urine sample. On receiving the specimens, the containers were labeled with the same code number of individual's questionnaire sheet. The students were advised to collect only terminal urine samples and return immediately. The collection of samples was carried out between 10 am and $2 \mathrm{pm}$ since this is a period during which eggs of S.haematobium are more likely to be passed in urine. ${ }^{12}$ Instructions were given to the children to conduct physical exercise prior to urine collection to improve egg-detection. For each urine sample the following was done:

i. Detection of visible haematuria (macrohaematuria)

ii. Detection of microhematuria by chemical reagent strips test (Urorocolor, 9SD, Standard Diagnostics, Korea).

The Detection and counting of S.haematobium eggs by microscopically examination was done using centrifugation sedimentation technique. ${ }^{13}$ Also detection and counting of S.haematobium eggs microscopically was done using filtration technique. ${ }^{14}$ The data collected, revised, coded and fed to statistical software SPSS version 21. Statistical analysis was done using SPSS.

\section{Results}

480 urine samples were collected and screened for S.haematobium using urine centrifugation technique and filtration technique. The numbers of infected cases for S.haematobium in urine samples were $46(9.6 \%)$ using urine centrifugation technique and 54(11.3\%) using filtration techniques; (Table 1).

Table I The number and percentage of infected and non infected cases with S.haematobium using the urine centrifugation and filtration techniques

\begin{tabular}{lll}
\hline Techniques & $\begin{array}{l}\text { Urine centrifugation } \\
\text { technique }\end{array}$ & Filtration technique \\
Cases & & \\
\hline Infected cases & $46(9.6 \%)$ & $54(11.3 \%)$ \\
Non infected cases & $434(90.4 \%)$ & $426(88.7 \%)$ \\
Total & $480(100 \%)$ & $480(100 \%)$ \\
\hline
\end{tabular}

Prevalence of infection according to age group

The age of students were grouped into three groups; age group one, age group two and age group three which represent the age of 5-8, 9-12, over 12 years respectively; (Table 2).

Table 2 The number and percentage of infected cases with S.haematobium using the urine centrifugation and filtration techniques correlated with age group

\begin{tabular}{lll}
\hline \multicolumn{1}{c}{ Age groups } & $\begin{array}{l}\text { Urine } \\
\text { centrifugation } \\
\text { technique }\end{array}$ & $\begin{array}{l}\text { Filtration } \\
\text { technique }\end{array}$ \\
\hline $5-8$ years & $12(26.1 \%)$ & $18(33.3 \%)$ \\
$9-12$ years & $28(60.8 \%)$ & $30(55.6 \%)$ \\
Over 12 years & $6(13 \%)$ & $6(11.1)$ \\
Total & $46(100 \%)$ & $54(100 \%)$ \\
\hline
\end{tabular}

\section{Prevalence of infection according to sex}

480 urine samples examined, $382(79.6 \%)$ were male and 98(20.4\%) were female; (Table 3).

Table 3 The number and percentage of infected cases with S.haematobium in relation to sex using the urine centrifugation and filtration techniques

\begin{tabular}{lll}
\hline Sechniques & $\begin{array}{l}\text { Urine } \\
\text { centrifugation } \\
\text { technique }\end{array}$ & Filtration technique \\
\hline Male & $42(91.3 \%)$ & $50(92.6 \%)$ \\
Female & $4(8.7 \%)$ & $4(7.4 \%)$ \\
Total & $46(100 \%)$ & $54(100 \%)$ \\
\hline
\end{tabular}

Prevalence of infection according to presence or absence of latrine

480 urine samples investigated $139(29 \%)$ have latrines and while 341(71\%) without latrines; (Table 4).

Table 4 The number and percentage of infected cases with S.haematobium according to the latrine facility using the urine centrifugation and filtration techniques

\begin{tabular}{lll}
\hline \multicolumn{1}{c}{ Techniques } & $\begin{array}{l}\text { Urine centrifugation } \\
\text { technique }\end{array}$ & Filtration technique \\
\hline Cases & $15(32.6 \%)$ & $15(27.8 \%)$ \\
Absence & $31(67.4 \%)$ & $39(72.2 \%)$ \\
Total & $46(100 \%)$ & $54(100 \%)$ \\
\hline
\end{tabular}

\section{Prevalence of infection according to source of drinking water}

480 urine samples examined from students drink from pipe were $100(20.8 \%)$, from canals were $260(54.2 \%)$ and from donkey cart were $120(25 \%)$; (Table 5).

Table 5 The number and percentage of infected cases with S.haematobium according to source of drinking water using the urine centrifugation and filtration techniques

\begin{tabular}{lll}
\hline Techniques & $\begin{array}{l}\text { Urine centrifugation } \\
\text { technique }\end{array}$ & Filtration technique \\
\hline Pipe & $8(17.4 \%)$ & $10(18.5 \%)$ \\
Canal & $33(71.7 \%)$ & $33(61.1 \%)$ \\
Donkey cart & $5(10.9 \%)$ & $11(20.4 \%)$ \\
Total & $46(100 \%)$ & $54(100 \%)$ \\
\hline
\end{tabular}




\section{Prevalence of infection according to family occupation}

480 urine samples examined families of students farmer were $150(31.3 \%)$, employee were $80(16.7 \%)$, laborers were 190(39.6\%) and others 60(12.5\%); (Table 6).

Table 6 The number and percentage of infected cases with S.haematobium according to family occupation using the urine centrifugation and filtration techniques

\begin{tabular}{lll}
\hline Cases & $\begin{array}{l}\text { Urine centrifugation } \\
\text { technique }\end{array}$ & Filtration technique \\
\hline Farmer & $28(60.8 \%)$ & $30(55.6 \%)$ \\
Employee & $0(00.0 \%)$ & $0(00.0 \%)$ \\
Laborer & $15(32.7 \%)$ & $15(27.8 \%)$ \\
Others & $3(6.5 \%)$ & $9(16.6 \%)$ \\
Total & $46(100 \%)$ & $54(100 \%)$ \\
\hline
\end{tabular}

Prevalence of infection according to contact or not contact to water

480 urine samples investigated $350(72.9 \%)$ are contact and while $130(27.1 \%)$ without contact to water; (Table 7).

Table 7 The number and percentage of infected cases with S.haematobium according to the contact or not contact to water using the urine centrifugation and filtration techniques

\begin{tabular}{lll}
\multicolumn{1}{c}{ Techniques } & $\begin{array}{l}\text { Urine centrifugation } \\
\text { technique }\end{array}$ & Filtration technique \\
\hline Cases & $32(69.6 \%)$ & $34(62.9 \%)$ \\
Not contact & $14(30.4 \%)$ & $20(37.1 \%)$ \\
Total & $46(100 \%)$ & $54(100 \%)$ \\
\hline
\end{tabular}

Prevalence of infection according to presence or absence of micro-haematuria

480 urine samples investigated $188(39.2 \%)$ have haematuria and while 292(60.8\%) without haematuria; (Table 8).

Table 8 The number and percentage of infected cases with S.haematobium according to the haematuria using the urine centrifugation and filtration techniques

\begin{tabular}{lll}
\hline Techniques & $\begin{array}{l}\text { Urine centrifugation } \\
\text { technique }\end{array}$ & Filtration technique \\
\hline Presence & $46(100 \%)$ & $54(100 \%)$ \\
Absence & $0(0.0 \%)$ & $0(0.0 \%)$ \\
Total & $46(100 \%)$ & $54(100 \%)$ \\
\hline
\end{tabular}

\section{Discussion}

This study was conducted in White Nile Sugar Scheme campus in El-Qeteena locality White Nile State among basic school children to determine the prevalence of Urinary Schistosomiasis, and to assess the environmental and socioeconomic factor influencing the spread of the disease during the period from December 2014-April 2015. The study recorded prevalence of $(11.3 \%)$ for urinary Schistosomiasis. The prevalence was high among males $(92.6 \%)$ than females (7.4 $\%$ ) for urinary Schistosomiasis. This is in accordance to the results obtained by Gala Eldin ${ }^{15}$ who found a prevalence of $57.5 \%$ for males, $42.5 \%$ for females for S. haematobium Assalaya Sugar Scheme at White Nile State. Comparable result was also found in Ghana with the prevalence of $56.3 \%$ among males and $44.7 \%$ among females for S.haematobium. ${ }^{16}$ The study showed high prevalence of urinary Schistosomiasis among age group (9-12) years which reach up to $61.2 \%$. This result agreed with those of Hilali \& WHO, ${ }^{17,18}$ who found prevalences of $55.2 \%, 40.7 \%$ and $57.5 \%$, respectively for both species in the same age groups. The study investigated the prevalence of urinary Schistosomiasis in relation to latrine facilities. The infection was high among those who have no latrine facilities $(72.2 \%)$ for urinary Schistosomiasis. This result agree with Hilali \& El-Katsha ${ }^{18,19}$ whom found the disease transmission was related to contamination of water as washing the urethral orifices after urination and bad sanitation of water bodies. Many other factors were found to contribute in transmission of the disease among them were family occupation and sources of drinking water and the poor people are more susceptible to disease. Sex and age parameters, which show differences in transmission, school children are more infected than others. The prevalence of urinary Schistosomiasis according to the source of drinking water, was found to be high among those who drink from canals, $(18.5 \%)$ from those who have healthy water (47.9 $\%)$ for urinary. According to water contact the study showed a high prevalence of $(62.9 \%)$ for urinary Schistosomiasis among those with frequent contact to water. This could be explained by the fact that contact to water is the main cause of infection as it is evident from this study which revealed high prevalence of urinary Schistosomiasis in relation to occupation. The prevalence among the farmer was $(55.6 \%)$ because they work in culturing and irrigation of sugar cane which subject them to repeated exposure during working.

\section{Conclusion}

The findings of this study indicate that the prevalence of urinary Schistosomiasis in the study area was $11.3 \%$. The prevalence of Urinary Schistosomiasis was high among boys than girls in the study areas. The age group (9-12) years was the most affected with prevalence of $55.6 \%$. Our results suggest the association of any irrigated scheme with the prevalence of urinary schistosomiasis in developing countries. The bad sanitation and lack of healthy drinking water were the major causes of infection. We recommended any new irrigated Scheme might be far from population especially school children.

\section{Acknowledgements}

None.

\section{Conflict of intertest}

The author declares no conflict of interest.

\section{References}

1. Gryseels B, Polman K, Clerinx J, et al. Human Schistosomiasis. Lancet. 2006;368(9541):1106-1118.

2. WHO. Prevention and control of schistosomiasis and soil-transmitted helminthiasis. Geneva, Switzerland: World Health Organ Tech Rep Ser. 2002;912(i-vi): 57.

3. Steinmann P, Keiser J, Bos R, et al. Schistosomiasis and water resources development: systematic review, meta-analysis and estimates of people at risk. Lancet Infect Dis. 2006;6(7):411-425.

4. Hotez PJ, Brown AS. Neglected tropical disease vaccines. Biologicals. 2009;37(3):160-164. 
5. King CH, Dickman K, Tisch DJ. Reassessment of the cost of chronic helmintic infection: a meta-analysis of disability-related outcomes in endemic schistosomiasis. Lancet. 2005;365(9470):1561-1569.

6. Hotez PJ, Molyneux DH, Fenwick A, et al. Control of neglected tropical diseases. N Eng J Med. 2007;357(10):1018-1027.

7. Watts S. The social determinants of schistosomiasis. Geneva, Switzerland: WHO; 2005. p. 1-10.

8. Engels D, Chitsulo L. Schistosomiasis. In: Crompton DW, Montresor A, Nesheim, editors. Controlling disease due to helminth infections. Geneva, Switzerland: WHO; 2003. p. 15-21.

9. Akinwale OP, Ajayi MB, Akande DO, et al. Urinary Schistosomiasis around Oyan Reservoir, Nigeria: Twenty Years after the First. Outbreak. Iranian J Publ Health. 2010;39(1):92-95.

10. WHO. Pesticides and their application for the Control Vectors and pests of public health importance. $6^{\text {th }}$ ed. Original office, Geneva, Switzerlanmd: World Health Organization; 2006. 114 p.

11. Tamomh AG, Yousfi SR, Abakar AD, et al. Prevalence of intestinal schistosomiasis among basic school children in White Nile Sugar Scheme a New Irrigated Project, White Nile State, Sudan. Biol Med (Aligarh). 2018;10:425.
12. Lucas AO, Gilles HM. A new short textbook of preventive medicine for the tropics. 3rd ed. London: Hodder Arnold; 1990.

13. Cheesbrough M. Medical laboratory manual for developing countries. volume 1. 2nd ed. 1999;2:236.

14. Cheesbrough M. Medical laboratory manual for tropical countries. volume 1. 2nd ed. Oxford; 1992

15. Gala Eldin A, Abdelrhman. The prevalence of Schistosomiasis among the Basic School Children At Asslaya Campus White Nile State 2006-2007. Sudan: University of Khartoum; 2007. p .1-48.

16. Klump RK, Webbe G. Focal, seasonal and behavioral patterns of infection and transmission of $S$. haematobium in farming villages at the Volta Lake, Ghana. J Trop Med and Hyg. 1987;90(5):265-281.

17. WHO. Report of the WHO informal consultation on schistosomiasis control. Geneva, Switzerland: WHO; 1998. 45 p.

18. Hilali AH, Madsen H, Daffalla AA, et al. Infection and transmission of Schistosoma mansoni in the Managil area, Sudan. Ann Trop Med Parasitol. 1995;89(3):279-286.

19. El-Katsha S, Watts S. Gender, behavior and health: Schistosomiasis transmission and control in rural Egypt. The University of Chicago Press. 2005;53(4):1005-1009. 